This item was submitted to Loughborough's Research Repository by the author.

Items in Figshare are protected by copyright, with all rights reserved, unless otherwise indicated.

\title{
Investigating children's understanding of inversion using the missing number paradigm
}

PLEASE CITE THE PUBLISHED VERSION

http://www.elsevier.com/wps/find/journaldescription.cws_home/620192/description\#description

PUBLISHER

(C) Elsevier

VERSION

AM (Accepted Manuscript)

LICENCE

CC BY-NC-ND 4.0

\section{REPOSITORY RECORD}

Gilmore, Camilla K.. 2019. “Investigating Children's Understanding of Inversion Using the Missing Number Paradigm”. figshare. https://hdl.handle.net/2134/8761. 
This item was submitted to Loughborough's Institutional Repository (https://dspace.lboro.ac.uk/) by the author and is made available under the following Creative Commons Licence conditions.

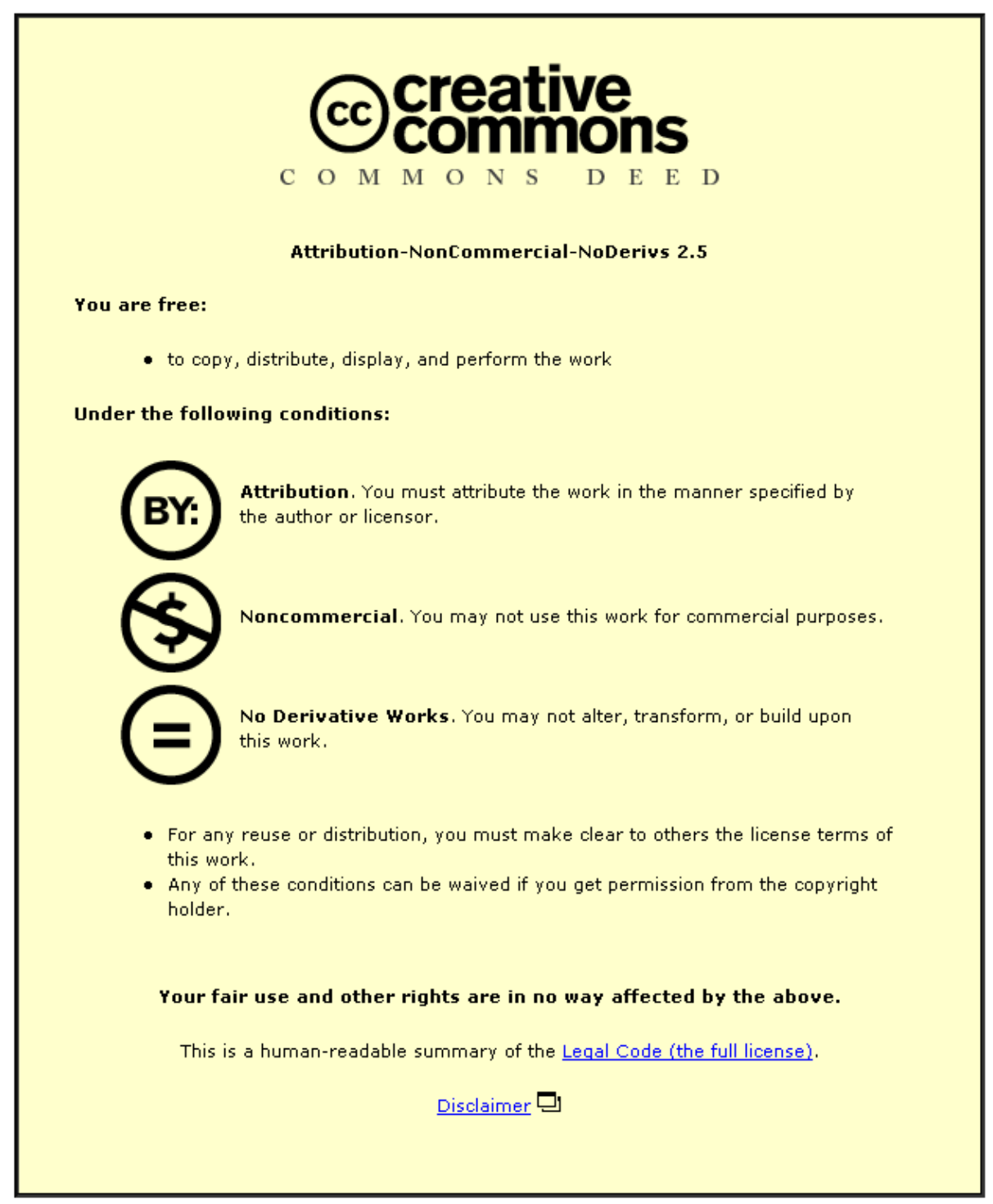

For the full text of this licence, please go to: http://creativecommons.org/licenses/by-nc-nd/2.5/ 


\title{
Running head: CHILDREN'S UNDERSTANDING OF INVERSION
}

Investigating children's understanding of inversion using the missing number paradigm

\author{
Camilla K Gilmore
}

University of Oxford

This paper was published in Cognitive Development (2006), 21, 301-316 doi:10.1016/j.cogdev.2006.03.007 


\begin{abstract}
The development of conceptual understanding in arithmetic is a gradual process and children may make use of a concept in some situations before others. Previous research has demonstrated that when children are given arithmetic problems with an inverse relationship they can infer that the initial and final quantities are the same (e.g. $15+8-8=\square)$. However we don't know whether children can perform the complementary inference that if the initial and final quantities are the same there must be an inverse relationship (i.e. $15+\square-8=15$ or $15+8-\square=15$ ). This paper reports two experiments that presented inverse problems in a missing number paradigm to test whether children (aged $8-9$ ) could perform both these types of inferences. Children were more accurate on standard inverse problems $(a+b-b=a)$ than on control problems $(a+b-c=d)$, and their performance was best of all on rearranged inverse problems $(b-b+a=a)$. The children's performance on inverse problems was affected by the position of the missing number and also by the order of elements within the problem. This may be due to the different types of inferences that children must make to solve these kinds of inverse problems.
\end{abstract}

Keywords: Arithmetic, concepts, problem solving. 
Investigating children's understanding of inversion using the missing number paradigm

Understanding of arithmetic essentially involves understanding of relationships - relationships among sets of numbers and relationships between operators. Thus, the development of arithmetical expertise involves not only learning to perform procedures accurately but also understanding the key concepts and principles that underlie these procedures. Early theories of arithmetic development suggested that understanding of arithmetic concepts may develop independently from learning arithmetic procedures and debated which developed first (e.g. Briars \& Siegler, 1984; Riley, Greeno, \& Heller, 1983). This led to attempts to establish the ages at which children understood particular concepts and could use certain procedures (e.g. Baroody \& Gannon, 1984). More recently there has been an acknowledgement that the development of conceptual understanding may be more gradual and closely related to advances in procedural skill.

The iterative model of arithmetic development (Byrnes, 1992; Byrnes \& Wasik, 1991; Hiebert \& Wearne, 1996; Rittle-Johnson \& Alibali, 1999; RittleJohnson \& Siegler, 1998; Rittle-Johnson, Siegler, \& Alibali, 2001) proposes that conceptual knowledge and procedural knowledge of arithmetic develop together. Advances in one type of knowledge can lead to advances in the other, which may then allow further development of the first. Thus, there is a bidirectional, causal relationship between the developments of each type of knowledge (Rittle-Johnson et al., 2001). As a result, children may have partial knowledge of concepts and procedures, which at first may not be integrated (Bisanz \& LeFevre, 1992; Carpenter, 1986). Therefore, at any point in time it will be inappropriate to attempt to judge 
whether children do or do not 'have' conceptual or procedural knowledge of a domain.

In keeping with this model, two theories of conceptual development have emphasized the gradual development in understanding of arithmetic concepts. Vergnaud $(1982,1990,1997,1998)$ introduced the idea of conceptual fields as a means to describe the nature of conceptual knowledge and how it drives problem solving in mathematics. When learning mathematics, children acquire different properties of the same concept, or apply the same concept in different situations, over a long period of time. Some aspects of a concept may be mastered many years before others. He proposed that it is therefore important to consider the range of situations to which mathematical concepts are relevant. By examining these situations and the different knowledge that is required, we can explain why children find certain problems more difficult than others.

Baroody (Baroody \& Ginsburg, 1986; Baroody \& Tiilikainen, 2003) draws on the concept of a schema as an important knowledge structure. Children's schemata for different concepts develop from being example-driven and context-bound to being principle-driven, generalized and abstract. This series of weak and progressively stronger schemata mean that at any stage children's understanding of arithmetic principles is not all-or-none. Some aspects of a concept may be developed but not others. Both these theoretical approaches consider conceptual knowledge to play an integral role in driving problem solving. Furthermore, children acquire understanding of concepts in a piecemeal fashion and they may be able to make use of certain aspects before others.

This leads to the question of what it means to 'understand' a concept. Bisanz and LeFevre (1992) propose a framework that emphasizes the need to consider the 
situation in which understanding is assessed. Children may show understanding of a concept in one context but not another and these discrepancies can reflect potentially important differences in processes or representations. If children only demonstrate application of a procedure for one situation then this may possibly reflect rote learning, however successful performance on a range of problems indicates greater generality and possibly greater understanding. Within this framework, understanding is considered in terms of a profile of performance across a range of contexts, rather than performance on a single type of problem. Development can be represented as a sequence of profiles or spread of understanding across contextual space. This framework can be useful in capturing the subtle changes in children's understanding of a concept over development.

One of the most important concepts that children must grasp as they learn arithmetic is the inverse relationship between addition and subtraction. This is a key principle in arithmetic and underlies a number of other concepts and procedures. For example, the inverse relationship between addition and subtraction is a key aspect of additive composition. Also, understanding this relationship lessens the task of learning addition and subtraction number combination facts as children need only learn half of them and then can use their understanding of inverse relations to infer subtraction facts from addition, or vice-versa. It has thus been proposed that until children understand this relationship they cannot be said to fully comprehend addition or subtraction (Bryant, Christie, \& Rendu, 1999; Piaget, 1952; Piaget \& Moreau, 1977/2001; Vilette, 2002).

One way to test whether children understand the inverse relationship is to examine their performance on problems that involve inverse transformations. Some children can solve inversion problems $(\mathrm{a}+\mathrm{b}-\mathrm{b}=\square)$ by applying a conceptually 
based shortcut (i.e. responding 'a' directly) without performing successive computations (Bisanz, LeFevre, \& Gilliland, 1989; Bryant et al., 1999; Gilmore \& Bryant, in press; Rasmussen, Ho, \& Bisanz, 2003; Siegler \& Stern, 1998; Stern, 1992). Children who are aware that adding and then subtracting the same number will leave the original quantity unchanged, will be able to solve problems like this quickly and accurately by responding with $a$, without the need for computation. Alternatively, if children attempt to solve these problems by calculation, they are probably unaware of the inverse relationship and unable to use it to solve problems. Thus, if we give children problems that are difficult to solve by computation, then accuracy will be low and response times long when they solve these by calculation rather than the shortcut (Rasmussen et al., 2003). Therefore, if solutions are faster and more accurate for inverse problems $(a+b-b=)$ than control problems, which must be solved by computation $(\mathrm{a}+\mathrm{b}-\mathrm{c}=)$, this implies that children have made use of the conceptually-based shortcut which reveals they must understand the inverse relationship between addition and subtraction. Use of the conceptually-based shortcut does not, however, necessarily imply conscious awareness of this relationship.

We know that some children can make use of this principle from an early age. Children aged $6-11$ years were found to be faster at solving inverse problems (e.g. $4+5-5=\square$ ) than matched control problems (e.g. 4+5-7= $\square$ ) (Bisanz et al., 1989). If problems are presented in a supportive context some children who are even younger are able to make use of the inverse principle. Bryant et al. (1999) used blocks to present problems and found evidence of children making use of the principle from about the age of 5- or 6-years. In this study it was demonstrated that children's understanding of inversion appears to be in the full quantitative sense and not on the basis of identity. Children scored higher for inverse than control problems whether 
they were presented by adding and removing the same blocks or by adding and removing the same number of different blocks.

Children's understanding of inversion, however, is patchy. In previous studies only a subset of children used the inversion shortcut and they did not consistently apply the shortcut on all problems in which it would be appropriate. Only a quarter of the youngest children (aged 6) in the study by Bisanz et al. (1989) were users of the inversion shortcut, and this proportion did not substantially increase until the age of 11. Older children used the principle more extensively than younger children did, but they still did not do so in all possible situations. In a study by Rasmussen et al. (2003), only half the concretely presented inverse problems were solved correctly by preschoolers, and three-quarters by children in Grade one.

The conditions under which problems are presented (for example in mixed or separate blocks) has also been found to affect use of the shortcut, with children aged 8 to 10 years making more use of the inverse shortcut if inverse and control problems were presented in separate blocks (Stern, 1992). Finally, children may initially make unconscious use of the principle before being able to verbalize how they are doing so (Siegler \& Stern, 1998). So, while there is evidence that children do understand this principle and can make use of the conceptual shortcut, they do not do so in all appropriate situations.

All of the previous studies of inversion have only assessed children's performance on canonical problems in which the sum was missing $(a+b-b=\square)$. However, as highlighted above conceptual development is not all-or-none and we therefore need to examine children's understanding of inversion in different situations to reveal their profile of performance across a range of problem types. The important question is not whether children understand inversion but how well they can use it in 
various situations. If children are able to use the inverse principle flexibly across a range of situations then this will suggest that their understanding of this concept is fully developed and has become abstract and generalisable (Rittle-Johnson et al., 2001). Alternatively if children are able to recognize and take advantage of the inverse relationship more easily for some problem situations than others then this will suggest that their understanding of this concept is still developing and may reveal which aspects of the concept develop earlier than others. As Vergnaud (1997) highlighted, by examining the knowledge required in different problem situations we can explain why children find some problems more difficult than others.

There is a much wider range of problems which involve inverse relations than have been previously used and these may pose different challenges to children. In particular we can vary the position of the missing number in inverse problems (e.g. $\mathrm{a}+\mathrm{b}-\mathrm{b}=\square ; \mathrm{a}+\mathrm{b}-\square=\mathrm{a} ; \mathrm{a}+\square-\mathrm{b}=\mathrm{a} ; \square+\mathrm{b}-\mathrm{b}=\mathrm{a})$. If children have a complete understanding of the principle, they should be able to apply it even to problems which do not take the standard canonical form. So if children can use the inversion principle consistently and flexibly, they should do better on inverse problems such as $15+8-$ $8=\square ; 15+8-\square=15 ; 15+\square-8=15 ; \square+8-8=15$ than on equivalent problems such as $14+9-5=\square ; 14+9-\square=18 ; 14+\square-5=18 ; \square+9-5=18$, to which the inversion principle could not be applied and which therefore have to be solved by straight computation.

Crucially, varying the position of the missing number in inverse problems allows us to distinguish two different classes of inverse problems. For problems with either the ' $a$ ' term or the sum missing (e.g. standard canonical problems $a+b-b=\square$; or those with the missing number in the first position $\square+b-b=a$ ) children are given the information that the ' $b$ ' terms cancel each other out (i.e. the inverse relationship) 
and they have to infer that the unknown is therefore equal to ' $a$ '. In contrast for problems where the missing number is either the ' $+\mathrm{b}$ ' or ' $-\mathrm{b}$ ' term $(a+b-\square=a$; $\mathrm{a}+\square-\mathrm{b}=\mathrm{a}$ ) children are given the information that the final sum is equal to ' $\mathrm{a}$ ' and they have to infer that the remaining elements cancel each other out and therefore that the unknown is equal to 'b' (i.e. infer the inverse relationship). Thus the premise of one type of problem is the inference in the other and vice-versa.

Previous work considering children's performance on canonical problems has only tested children's ability to perform the first type of inference. We need to present inverse problems within a missing number paradigm in order to test children's ability to perform the second type of inference. These two inferences are related but different aspects of the concept of inversion. If children have reasonably thorough understanding of the inverse relationship between addition and subtraction then we would expect that they would be able to perform both these types of inference. However, the second type of inference is a potentially more complex aspect of the concept. Children might quite often experience situations where an addend and subtrahend cancel each other out and the result is no change. They should, as a result, be reasonably able to infer that there is no change when they are given the information that the addend and subtrahend have the same number. However, it is unlikely that they often have to infer that the addend and subtrahend must have been the same when the starting point and the final sum are equal. Thus a tentative prediction is that children will find the second type of inference more difficult than the first. Previous work has not presented children with problem situations requiring both types of inferences and so children's ability to perform this second type of inference has never been tested. 
A further manipulation that will allow us to test children's ability to use the concept of inversion in different situations is to vary the way that problems are presented. Arithmetic problems may be framed in abstract digit format (e.g. $5+9=$ ) or a more context-rich story format (e.g. John had 5 marbles, then he was given 9 more marbles, how many marbles does he have now?). It is possible that children will be more likely to recognize and take advantage of inverse relationships when more context is provided. This effect may furthermore interact with the type of inverse situation determined by the position of the missing number. The advantage of added context may be greater for inverse situations that children find more difficult to recognize.

We know from previous work that the position of the missing number is one factor that affects children's performance in standard arithmetic problems (Carpenter \& Moser, 1982; de Corte \& Verschaffel, 1987; Grouws, 1972; Lindvall \& Ibarra, 1980; Nesher, 1982; Riley, et al., 1983; Verschaffel \& de Corte, 1997; Weaver, 1971). Children find problems with the missing number in the first position (e.g. $\square+2=11$ ) more difficult than those with the missing number in the second position (e.g. $7+\square=13$ ), which are more difficult than standard canonical problems with the answer missing (e.g. $5+9=\square$ ). We do not know whether the effects of varying the position of the missing number will be an important factor in determining children's success on arithmetic problems that can be solved using a conceptually-based shortcut.

This paper presents the results of two studies that were carried out to examine the effect of varying the missing number on children's performance on inverse problems. The missing number paradigm has never been applied to the study of children's use of the inversion principle. Children aged $8-9$ were given inverse and 
control problems within a missing number paradigm. In the first study the effect of the missing number was examined in standard and inverse problems and for problems presented in digit or word form. In the second study the effect of varying both the order of elements in the problem, and the position of the missing number, was examined in more detail for digit problems.

\section{Experiment 1}

\section{Method}

Participants. Forty-nine children (20 boys and 29 girls) from a state primary school took part in the study. They were from two parallel Year 4 classes with mean age 9 years 1 month and $S D 3.3$ months. All participants spoke English as their first language and no child had a statement of special educational needs.

Design and materials. A within-subject design with three factors was used. The first factor was the type of problem (inversion or control); the second factor was the type of presentation (word or digit); and the final factor was the position of the missing number (first, second, third or fourth).

Children were presented with 64 four-element problems $(a+b-c=d)$ on $a$ laptop computer. There were 32 different mathematical problems, each presented in both digit and word format. In each problem, one of the numbers was missing and the child was asked to supply it (e.g. digit problem with missing number in position 2 : $13+\square-9=13$; word problem with missing number in position 1: 'Daniel had some cards, he found 7 more and then lost 7 . At the end he had 13. How many did he have to start with?'). All of the word problems were from the semantic category of Change problems (Carpenter \& Moser, 1982). This ensured that children's performance would not be affected by the semantic structure of the problems. 
Half of the questions were inversion problems (where $b=c$ and $a=d$; e.g. $16+14-\square=16$ ) and these were matched with a control problem that had the same missing number (e.g. $18+9-\square=13$ ). A subset of eight control problems had a repeated number in the problem (i.e. $\mathrm{a}=\mathrm{b}$ or $\mathrm{c}=\mathrm{d}$; e.g. $16+16-\square=24$ ). This was to check whether the children had adopted a response strategy of responding with the unrepeated number on inversion problems (e.g. responding ' 9 ' for $13+\square-9=13$ ) without fully understanding inversion. If this were the case, then it could artificially inflate the inversion effect. This strategy could be identified, however, because it would also lead to characteristic errors on this sub-set of control problems (e.g. responding ' 7 ' for $11+11-7=\square$ ).

The word problems were presented with images illustrating an aspect of the question with the word problem written underneath. The digit problems appeared in the center of the screen with an empty box in place of the missing number. Table 1 shows a set of matched inverse and control problems in word and digit format with the missing number in each position.

\section{Insert Table 1 About Here}

Procedure. The participants were tested individually in three sessions. The questions were split into three groups and ordered randomly with the following restrictions: half of the problems in each session were word and half digit presentation; half of the problems in each session were inverse and half control problems; there was a maximum of three consecutive inverse or control problems; there was a maximum of three consecutive word or digit problems. The order in which the sessions were completed was counterbalanced across participants in a Latin square. 
The task was introduced as a numbers game in which the participants had to work out the missing number. At the beginning of each session there were four familiarization / practice trials which were all control problems. Half of these involved word presentation and half digit presentation. In each trial the experimenter read the question aloud twice before the child responded. The children were given positive encouragement without any specific feedback throughout. Results

The aim was to discover the effect of problem type, position of the missing number and presentation format on the accuracy of participants' responses. Initial analyses revealed that there was no effect of either session order or sex and so these factors were removed from the analysis. A three-way repeated-measures analysis of variance was used to compare performance across the conditions. The three factors were problem type (inverse, control), presentation (digit, word) and position of the missing number $(1,2,3,4)$. The measure of performance was the proportion of correct responses to each problem type.

There was a highly significant problem type effect $(F(1,48)=150.011, p<$ $\left.0.001, \eta_{\mathrm{p}}{ }^{2}=0.758\right)$ : accuracy was higher for inverse than for control problems. This effect was constant across both types of presentation and for all problems regardless of the position of the missing number. So the children used the inversion principle in non-canonical as well as in canonical problems.

A subset of control problems were included that involved a repeated digit (e.g. $11+11-7=\square$ ) to test whether children were using a superficial strategy of responding with the unrepeated digit. There was only a very low level of this characteristic type of error: only $0.8 \%$ of responses on this set of problems were errors of responding with the unrepeated number. This suggests that the more accurate 
performance on inverse problems was not due to children employing this superficial strategy.

There was an effect of the position of the missing number on children's performance $\left(F(3,46)=79.848, p<0.001, \eta_{\mathrm{p}}{ }^{2}=0.839\right)$. This effect was qualified by an interaction between the position of the missing number and problem type $(F(3,46)$ $\left.=8.909, p<0.001, \eta_{\mathrm{p}}{ }^{2}=0.367\right)$. This interaction is demonstrated in Figure 1. There was a significant advantage for inverse problems over control problems with the missing number in each position, but the effects of the missing number were slightly different for inverse and control problems. Post-hoc comparisons with Bonferroni correction (all at $p<0.001$ ) revealed that for inverse problems accuracy was significantly lower for problems with the missing number in Position 1 (mean $=$ $0.513)$ than in Position $2($ mean $=0.691)$ and accuracy was significantly lower for problems with the missing number in Position 2 than in Position $3($ mean $=0.806)$. There was no difference in accuracy for problems with the missing number in Position 3 or in Position 4 (mean $=0.870)$. In contrast, for control problems accuracy was lower for problems with the missing number in Position $1($ mean $=0.153)$ and in Position $2($ mean $=0.189)$ than for problems with the missing number in Position 3 $($ mean $=0.482)$ and in Position $4($ mean $=0.518)$. But there was no difference in accuracy between problems with the missing number in Position 1 or in Position 2 or between problems with the missing number in Position 3 or in Position 4.

Insert Figure 1 About Here

There was no significant difference between word and digit presentation overall $(F(1,48)<1)$. However there was an interaction between presentation format and the position of the missing number $\left(F(3,46)=5.566, p=0.002, \eta_{\mathrm{p}}{ }^{2}=0.266\right)$. There was no difference in performance between digit and word problems with the 
missing number in Position $1(F(1,48)<1)$, Position $3(F(1,48)=1.427$, n.s. $)$ or Position $4(F(1,48)<1)$. On the other hand, for problems with the missing number in Position 2, performance was better with word presentation $($ mean $=0.487)$ than digit presentation $\left(\right.$ mean $\left.=0.393 ; F(1,48)=7.326, p=0.009, \eta_{\mathrm{p}}^{2}=0.132\right)$.

\section{Discussion}

Children's responses were more accurate for inverse than control problems regardless of the position of the missing number. This reveals that children were making use of the inverse shortcut to solve inverse problems with the missing number in different positions. The children were more accurate on inverse than control problems both when they were given information about the inverse relationship $(+b-$ b) and they had to infer that the unknown was equal to ' $a$ ' and when they were given the information that the sum and 'a' term were equal and they had to infer the inverse relationship. Thus it appears that children are able to perform both these types of inferences. The relative difficulty of performing these two types of inferences interacted with the position of the missing number. Children were better at the first type of inference than the second with the sum missing but worse with the 'a' term missing.

The way that problems were presented did not have a great effect on children's performance. There was an advantage of using word problems but only when the missing number was in Position 2. The mixed effect of word problem format may be due to an interaction between positive and negative effects. Children may be aided by word problems as they provide more contextual information. However, at the same time these problems make more verbal and semantic demands than numerical formats. Thus the combined effect of these two factors may lead to no overall advantage of word over digit format. The relative costs and benefits of using word problems may 
differ across the different problem situations (i.e. with the missing number in different positions) and thus the interaction between missing number and presentation may occur because the benefits outweigh the costs only for the situation where the missing number is in Position 2.

The relatively slight benefit of the addend context inherent in word problems may be in part due to the use of change word problems (e.g. Joe had 3 marbles. Then Tom gave him 5 more marbles. How many marbles does Joe have now?). Word problems with this structure are psychologically non-commutative (de Corte \& Verschaffel, 1987). Children may therefore be reluctant to change the order of elements in these problems and thus may not use their understanding of inversion. On the other hand, combine word problems (e.g. Joe has 3 marbles. Tom has 5 marbles. How many marbles do they have altogether?) are psychologically commutative and so children may be more prepared to change the order of the elements. Therefore greater benefits of using word problems may be found if the problems have a combine rather than change structure.

The position of the missing number affected performance for both inverse and control problems. Children were more hampered in using the inverse shortcut to solve problems with the missing number towards the start of the sum. The position of the missing number had a similar effect for both inverse and control problems. For both types of problem, accuracy was higher with the missing number closer to the end of the sum. Although there were slight differences in where the significant differences lay, the pattern of means were the same. Thus, although the children were using different processes to solve the inverse and control problems (namely the inverse shortcut and computation respectively) these processes were similarly interrupted when the missing number was in a non-canonical position. 
There are two factors that may lead to children's difficulties on inverse problems with the missing number towards the start of the sum. It may be the position of the missing number that causes these difficulties or alternatively the status of the missing number may be the important factor.

Each element in inverse problems $(a+b-b=a)$ plays a different role. When the unknown element is varied for inverse problems, it is not only the position of the missing number that changes but also the status of the missing number. In the problems used so far, these factors have been confounded. For example, if we compare children's performance on inverse problems with the missing number in Position 1 or 2 , then we are actually comparing a problem with the ' $a$ ' term missing in Position 1 to a problem with the ' $+\mathrm{b}$ ' term missing in Position 2. We need to use a wider variety of inverse problems to separate these effects. Experiment 2 was carried out to examine children's performance on problems that allow the effects of these factors to be separated.

\section{Experiment 2}

Experiment 2 was carried out to investigate whether the position of the missing number or the status of the missing number in an inverse problem was important in determining its difficulty. The type of inversion problems used in Experiment 1 and all previous studies (i.e. $a+b-b=a)$ is not the only type of problem to which the inversion shortcut is applicable. The order of elements in the problem can be rearranged (e.g. $b-b+a=a)$. These problems can also be solved either by repeated computation, or by applying a shortcut based on the inverse principle.

We can use these two types of inverse problem to discover whether the effects of the unknown are due to the position or the status of the missing number. If the effects were due to the position of the missing number then we would expect children 
to find the problems with the first element missing the most difficult for both original and rearranged problems (i.e. $\square+b-b=a$ and $\square-b+a=a)$. If, however, the effects were due to the status of the missing number, then we would expect children to have the most difficulties when the 'a' term was missing, regardless of its position (i.e. $\square+b-b=a$ and $b-b+\square=a)$.

Children's use of the inversion shortcut on problems with the order b$\mathrm{b}+\mathrm{a}=\mathrm{a}$ has not been previously examined. This experiment will also demonstrate whether children can apply the shortcut to the same extent on this new type of inversion problem as on inversion problems that have been previously used $(\mathrm{a}+\mathrm{b}-$ $b=a)$.

Method

Participants. Fifty-one children (26 boys and 25 girls) took part in the study. They were from Year 4 classes with mean age 9 years 5 months and $S D 3.5$ months. All participants spoke English as their first language and no child had a statement of special educational needs.

Design and materials. A within-subject design with three factors was used. The first factor was the type of problem (inversion or control); the second factor was the order of elements (standard or rearranged); and the final factor was the position of the missing number $(1,2,3,4)$.

Children were presented with 48 four-element problems on a laptop computer. All the problems were in digit format and appeared in the center of the screen with an empty box in place of the missing number. Half of the problems were inverse and half were control problems. Of these, half were in standard order $(a+b-b=a$ and $a+b-$ $c=d)$ and half were in the rearranged order $(b-b+a=a$ and $b-c+a=d)$. There were equal numbers of problems with the missing number in the first, second, third and 
fourth position. Thus the children completed three examples of each problem type. Examples of the different problem types can be found in Table 2.

\section{Insert Table 2 About Here}

Procedure. The participants were tested individually in two sessions. The questions were split into two groups so that there were equal numbers of inverse and control problems, standard and rearranged problems, and problems with the missing number in each position in each set. The order in which the sessions were completed was counterbalanced across participants. The problems were presented in a different random order for each participant.

The task was introduced as a numbers game and participants were asked to try to work out the missing number. At the beginning of each session there were two familiarization / practice trials to introduce children to the problem format. The experimenter read the question aloud twice before the child responded. The children were given encouragement without any specific feedback throughout.

Results

Different analyses were carried out to investigate the effects of (a) the position and (b) the status of the missing number.

Performance compared by the position of the missing number.

The accuracy of children's solutions was examined by comparing performance on standard and rearranged inverse problems and control problems according to the position of the missing number. This analysis is demonstrated in Figure 2. A threeway repeated-measures analysis of variance was used to compare performance across the conditions. The three factors were problem type (inverse, control), element order (standard, rearranged) and position of the missing number $(1,2,3,4)$. Initial analyses revealed that there was no effect of either session order or sex and so these factors 
were removed from the analysis. The measure of performance was the proportion of correct responses to each problem type.

Insert Figure 2 About Here

There was a main effect of problem type $\left(F(1,50)=140.388, p<0.001, \eta_{\mathrm{p}}{ }^{2}=\right.$ $0.737)$ with higher accuracy for inverse $($ mean $=0.675)$ than control $($ mean $=0.354)$ problems. The children were again more accurate for inverse than control problems regardless of the missing number and the element order. This indicates that they were able to make use of the inverse shortcut to solve all of the different inverse problem types.

There was also a main effect of element $\operatorname{order}(F(1,50)=11.045, p=0.002$, $\left.\eta_{\mathrm{p}}^{2}=0.181\right)$ with higher accuracy for rearranged (mean $\left.=0.549\right)$ than standard (mean $=0.480)$ problems. This main effect was qualified by a significant interaction between problem type and element $\operatorname{order}\left(F(1,50)=11.737, p=0.001, \eta_{\mathrm{p}}{ }^{2}=0.190\right)$. Analysis of this interaction revealed that accuracy was significantly higher on rearranged (mean $=0.737)$ than on standard $($ mean $=0.613)$ inverse problems $(F(1,50)=26.126, p<$ $\left.0.001, \eta_{\mathrm{p}}{ }^{2}=0.343\right)$. However there was no effect of element order on control problems $(F<1)$. Thus, it seems that children were able to apply the inverse shortcut more effectively for inverse problems in rearranged order $(b-b+a=a)$ than for standard inverse problems $(a+b-b=a)$.

Finally, there was a main effect of the position of the missing number $(F(3,48)$ $\left.=62.163 p<0.001, \eta_{\mathrm{p}}{ }^{2}=0.795\right)$. Post hoc comparisons with a Bonferroni correction (all at $p<0.001$ ) revealed that there was no difference in accuracy between problems with the missing number in Position $1($ mean $=0.333)$ and in Position 2 (mean $=$ 0.361). Accuracy was significantly lower for problems with the missing number in Position 2 than in Position 3 (mean $=0.626)$ and significantly lower for problems with 
the missing number in Position 3 than in Position 4 (mean $=0.737$ ). Importantly, the effects of the missing number were the same for standard and rearranged inverse problems. For both types of problem, children found those with the missing number in the first position the most difficult (i.e. $\square+b-b=a$ and $\square-b+a=a$ ).

In contrast to Experiment 1, the effects of the missing number were the same for inverse and control problems, and there was no difference in accuracy whether the missing number was in Position 1 or in Position 2, but there was a difference in accuracy between problems with the missing number in Position 3 and Position 4. Although the significant effects of the position of the missing number were not the same in Experiment 1 and 2, the same trend is shown in the pattern of means.

This analysis revealed that the position of the missing number plays a role in determining the difficulty of inverse problems. This factor can account for children's performance more consistently than the status of the missing number. The position of the missing number is not, however, sufficient to predict the difficulty of inverse problems. There was an unexpected effect of the order of elements in the inverse problems. Children were more successful on inverse problems in rearranged order $(b-b+a=a)$ than standard inverse problems $(a+b-b=a)$.

\section{Performance compared by status of the missing number.}

The next analysis examined the children's performance on inverse problems compared by the status of the missing number. This compared inverse problems with both standard and rearranged element order according to whether the 'a', ' $+\mathrm{b}$ ', ' $-\mathrm{b}$ ' or sum term was missing. This analysis was performed only for performance on inverse problems, because the terms in the control problems do not have such clearly defined roles $(a+b-c=d$ or $b-c+a=d)$. 
We carried out a two-way, $2 \times 4$, repeated measures analysis of variance in which the first factor was the order of elements in the problem (standard, rearranged) and the second factor the status of the missing number $(a,+b,-b$, sum). Figure 3 shows the effects of these factors.

\section{Insert Figure 3 About Here}

There was a significant main effect of element order $(F(1,50)=26.126, p<$ $\left.0.001, \eta_{\mathrm{p}}{ }^{2}=0.343\right)$ : accuracy was higher for problems in rearranged order $($ mean $=$ $0.549)$ than for problems in standard order $($ mean $=0.480)$. There was also a significant main effect of the status of the missing number $(F(3,48)=29.323, p<$ 0.001, $\left.\eta_{\mathrm{p}}{ }^{2}=0.647\right)$. Post-hoc tests with Bonferroni corrections show that the children's scores were significantly higher for problems with the sum $($ mean $=0.876)$ missing than for problems with the ' $a$ ' term $($ mean $=0.637)$, the ' $+b$ ' $($ mean $=0.533)$ term or the '-b' term $($ mean $=0.654)$ missing (all $p<0.001)$. The children's scores were significantly lower in problems with the ' $+b$ ' term missing in comparison both to problems with the 'a' term missing $(p=0.038)$ and also to problems with the '-b' term missing $(p<0.001)$.

There was also a significant interaction between element order and status of the missing number $\left(F(3,48)=10.734, p<0.001, \eta_{\mathrm{p}}{ }^{2}=0.402\right)$. For problems with the ' $\mathrm{a}$ ' term missing $\left(F(1,50)=44.678, p<0.001, \eta_{\mathrm{p}}{ }^{2}=0.472\right)$ or the sum missing $\left(F(1,50)=5.626, p=0.022, \eta_{\mathrm{p}}^{2}=0.101\right)$ scores were significantly higher for problems with the elements in rearranged than in standard order. In contrast, for problems with the ' $+b$ ' or '-b' terms missing the order of elements in the problems had no effect on children's performance $(F(1,50)=2.249$, n.s.; $F(1,50)=1.540$, n.s. $)$. Thus, if either of the inverse elements was missing, their position in the problem was 
not important. The order of elements within the sum was only important if one of the constants - the ' $a$ ' term or the sum - was missing.

\section{Discussion}

Experiment 2 examined children's performance on two types of inverse problems $(\mathrm{a}+\mathrm{b}-\mathrm{b}=\mathrm{a}$ and $\mathrm{b}-\mathrm{b}+\mathrm{a}=\mathrm{a})$ and control problems $(\mathrm{a}+\mathrm{b}-\mathrm{c}=\mathrm{d}$ and $\mathrm{b}-$ $\mathrm{c}+\mathrm{a}=\mathrm{d}$ ). For each type of problem we varied the identity of the unknown quantity. When children's performance was compared according to the position of the missing number, this was found to significantly affect scores on the different types of problem in similar ways. The children's scores were lowest for problems with the first number missing for both types of inverse problem and control problem. Thus, the position of the missing number rather than the status appears to be the important factor in causing children's difficulties.

Nevertheless, this factor alone cannot fully account for children's performance on the inverse problems. The children were more successful for inverse problems in rearranged order than standard order regardless of the position of the missing number. When children's performance on inverse problems was considered according to the status of the missing number, it was revealed that the order of the elements did not have an effect for problems with ' $+b$ ' or '-b' missing, but it did have a small effect if the 'sum' term was missing and a large effect if the 'a' term was missing. So the difficulties that children have with inverse problems, when the unknown quantity is varied, stem largely from the position of the missing number, but the order of elements in the problem is also an important factor.

\section{General Discussion}

Generally, the results of these experiments provide further evidence that children aged $8-9$ are reasonably competent in using the inverse principle to solve 
problems. This study also demonstrated for the first time that children can use the inverse principle on problems where they are given the information that the initial and final quantities are equal and they have to infer the inverse relationship. However, as with previous studies (Rasmussen et al., 2003; Stern, 1992) this work has shown that children's ability to use this concept is not complete. In Experiment 1 we showed that children were able to perform two types of inversion inference but the relative difficulty of these interacted with the identity of the missing number. In Experiment 2 we demonstrated that both the position of the missing number and the order of elements in the problem are important determinants of children's success on inverse problems.

For problems that required children to infer the inverse relationship (i.e. with one of the ' $b$ ' terms missing) the order of elements did not affect children's performance and they generally found this type of inference the more difficult. In contrast for problems that provided children with information about the inverse relationship and that required them to infer that the initial and final quantities were equal (i.e. with the 'a' term or sum missing), the order of elements did have an effect on children's accuracy. There are four problem types that require this type of inference and Table 3 summarizes the differences between them. By examining the differences between these problem situations in terms of the nature of the required inference we can reveal what factors affect the efficiency of children's reasoning.

\section{Insert Table 3 About Here}

Of the four problem types that require this type of inference, children find $b-$ $\mathrm{b}+\mathrm{a}=\square$ the simplest. For these problems a forward inference is needed, since the inference is about the final sum and is based on the information that precedes it. The unknown quantity and the ' $a$ ' term are adjacent (i.e. $0+a=\square$ ). For $a+b-b=\square$ 
problems, a forward inference is also required but the inverse elements intervene between the ' $a$ ' term and the unknown quantity (i.e. $a+0=\square$ ). Children found this type of problem somewhat more difficult. Problems like $b-b+\square=a$ were also more difficult. In these problems the unknown quantity and the 'sum' term were adjacent, but a backward inference was required because children had to work backwards from the sum to the unknown quantity in the preceding part of the equation (i.e. $0+\square=a$ ). The children found problems like $\square+b-b=a$ the most difficult. In these problems, it is necessary to make a backwards inference and the inverse elements intervene between the unknown quantity and the 'sum' term (i.e. $\square+0=a$ ).

So, it appears that children find it more difficult to make this type of inference in a backward than a forward direction, and they find it more difficult to make this type of inference when the inverse elements intervene between the 'a' or 'sum' term and the unknown quantity. These effects appear to be additive, so that children have particular difficulties on problems where a backward inference is required with a gap between the unknown and 'sum' term (i.e. $\square+b-b=a$ ).

The effects of directionality on inference making found in this study are in line with findings from other domains. When making causal inferences about the physical properties of objects, children find it easier to make cause-effect inferences than effect-cause inferences (Li, Zheng, Gao, Gao, \& Lin, 2005) and adults take less time to verify forward than backward inferences about conditional reasoning (Barrouillet, Grosset, \& Lecas, 2000).

The children in this study were able to apply the inverse shortcut to a different extent in different situations. This suggests that their understanding of inversion was still developing even at the age of 9 years-old. Thus, although some understanding of inversion has been demonstrated by children of 4-years-old (Rasmussen et al., 2003), 
this understanding may not be fully developed and applicable to all situations for many years. This emphasises that it is inappropriate to think of children 'having' or 'not having' a concept or to try to determine the specific age at which children acquire different concepts

Furthermore, these findings support the theories of arithmetical conceptual development of Vergnaud (1982, 1990, 1997, 1998) and Baroody (Baroody \& Ginsburg, 1986; Baroody \& Tiilikainen, 2003). Initially children may have limited understanding of arithmetic concepts, which they can only apply in a restricted range of situations. For example, they may only be able to use the inverse shortcut on canonical problems or only for problems presented in a certain way. Later, their understanding of the concept can be used more flexibly. This development takes place through a process in which localized knowledge structures (e.g. schemata for Baroody) become increasingly interconnected and the essential properties and relations are abstracted. Thus knowledge is a structural framework that guides the acquisition of new information. This process of conceptual development does not only apply to arithmetic but also in other domains where it is important to acquire conceptual understanding rather than simply rote procedural skills (e.g. science, engineering, geography, economics). The idea that children start with relatively nongeneralised, restricted contexts in which they can operate, and then develop a more generalised flexible understanding is also central to developmental theories more widely (e.g. Karmiloff-Smith, 1992).

This pattern of conceptual development has implications for education. Children's early conceptual knowledge in a domain will not be abstract but rather tied to specific problem situations. Thus, to help children develop sophisticated conceptual understanding it is important to ensure that they are exposed to different situations in 
which to apply their understanding in order for their limited local level concepts to develop into generalised abstract understanding. Indeed Vergnaud (1990) proposed that one important role of a teacher should be to provide a variety of situations in which children can apply their understanding.

Furthermore, when assessing children's conceptual understanding it is important that a range of different problem situations are included. Performance on a single task can only assess one aspect of children's understanding of a concept. The framework proposed by Bisanz and LeFevre (1992), which describes understanding as a profile of performance across conceptual space defined by different situations and activities, may be useful for this.

\section{References}

Baroody, A. J., \& Gannon, K. E. (1984). The development of the commutativity principle and economical addition strategies. Cognition and Instruction, 1, 321-339.

Baroody, A. J., \& Ginsburg, H. P. (1986). The relationship between initial meaningful and mechanical knowledge of arithmetic. In J. Hiebert (Ed.), Conceptual and procedural knowledge: The case of mathematics (pp. 75-112). Hillsdale, NJ: Erlbaum.

Baroody, A. J., \& Tiilikainen, S. H. (2003). Two perspectives on addition development. In A. J. Baroody \& A. Dowker (Eds.), The development of arithmetic concepts and skills: Constructing adaptive expertise (pp. 75-125). Mahwah, NJ: Erlbaum.

Barrouillet, P., Grosset, N., \& Lecas, J.-F. (2000). Conditional reasoning by mental models: Chronometric and developmental evidence. Cognition, 75, 237-266. 
Bisanz, J., \& LeFevre, J.-A. (1992). Understanding elementary mathematics. In J. I. D. Campbell (Ed.), The nature and origins of mathematical skills (pp. 113136). Amsterdam: Elsevier.

Bisanz, J., LeFevre, J.-A., \& Gilliland, S. (1989). Developmental changes in the use of logical principles in mental arithmetic. Poster presented at the biennial meeting of the Society for Research in Child Development, Kansas City.

Briars, D. J., \& Siegler, R. S. (1984). A featural analysis of preschoolers' counting knowledge. Developmental Psychology, 20, 607-618.

Bryant, P., Christie, C., \& Rendu, A. (1999). Children's understanding of the relation between addition and subtraction: Inversion, identity and decomposition. Journal of Experimental Child Psychology, 74, 194-212.

Byrnes, J. P. (1992). The conceptual basis of procedural learning. Cognitive Development, 7, 235-257.

Byrnes, J. P., \& Wasik, B. A. (1991). Role of conceptual knowledge in mathematical procedural learning. Developmental Psychology, 27, 777-786.

Carpenter, T. P. (1986). Conceptual knowledge as a foundation for procedural knowledge. In J. Hiebert (Ed.), Conceptual and procedural knowledge: The case of mathematics (pp. 113-132). Hillsdale, NJ: Erlbaum.

Carpenter, T. P., \& Moser, J. M. (1982). The development of addition and subtraction problem-solving skills. In T. P. Carpenter \& J. M. Moser \& T. A. Romberg (Eds.), Addition and Subtraction: A cognitive Perspective. Hillsdale, NJ: Erlbaum.

de Corte, E., \& Verschaffel, L. (1987). The effect of semantic structure on first graders' strategies for solving addition and subtraction word problems. Journal for Research in Mathematics Education, 18(5), 363-381. 
Gilmore, C.K. \& Bryant, P. (in press), Individual differences in children's understanding of inversion and arithmetical skill. British Journal of Educational Psychology.

Grouws, D. A. (1972). Open sentences: Some instructional considerations from research. Arithmetic Teacher, 19, 595-599.

Hiebert, J., \& Wearne, D. (1996). Instruction, understanding and skill in multidigit addition and subtraction. Cognition and Instruction, 14, 251-283.

Karmiloff-Smith, A. (1992). Beyond modularity. Cambridge, MA: MIT Press

Li, H., Zheng, C. J., Gao, X. M., Gao, S., \& Lin, G. D. (2005). The influence of complexity and reasoning direction on children's causal reasoning. Cognitive Development, 20, 87-101.

Lindvall, C. M., \& Ibarra, C. G. (1980). Incorrect procedures used by primary grade pupils in solving open addition and subtraction sentences. Journal for Research in Mathematics Education, 11(1), 50-62.

Nesher, P. (1982). Levels of description in the analysis of addition and subtraction word problems. In T. P. Carpenter \& J. M. Moser \& T. A. Romberg (Eds.), Addition and subtraction: A cognitive perspective. Hillsdale, NJ: Erlbaum.

Piaget, J. (1952). The child's conception of number. London: Routledge \& Kegan Paul.

Piaget, J., \& Moreau, A. (2001). The inversion of arithmetic operations. In J. Piaget (Ed.), Studies in reflecting abstraction (R.L. Campbell Trans., pp. 69-86). Hove, UK: Psychology Press. (Original work published 1977).

Rasmussen, C., Ho, E., \& Bisanz, J. (2003). Use of the mathematical principle of inversion in young children. Journal of Experimental Child Psychology, 85, 89-102. 
Riley, M., Greeno, J. G., \& Heller, J. I. (1983). Development of children's problem solving ability in arithmetic. In H. P. Ginsburg (Ed.), The development of mathematical thinking (pp. 153-196). New York: Academic Press.

Rittle-Johnson, B., \& Alibali, M. W. (1999). Conceptual and procedural knowledge of mathematics: Does one lead to the other? Journal of Educational Psychology, 91, 175-189.

Rittle-Johnson, B., \& Siegler, R. S. (1998). The relation between conceptual and procedural knowledge in learning mathematics: A review. In C. Donlan (Ed.), The development of mathematical skills (pp. 75-110). Hove, UK: Psychology Press.

Rittle-Johnson, B., Siegler, R. S., \& Alibali, M. W. (2001). Developing conceptual understanding and procedural skill in mathematics: An iterative process. Journal of Educational Psychology, 93, 346-362.

Siegler, R. S., \& Stern, E. (1998). Conscious and unconscious strategy discoveries: A microgenetic analysis. Journal of Experimental Psychology - General, 127, 377-397.

Stern, E. (1992). Spontaneous use of conceptual mathematical knowledge in elementary school children. Contemporary Educational Psychology, 17, 266277.

Vergnaud, G. (1982). A Classification of cognitive tasks and operations of thought involved in addition and subtraction problems. In T. P. Carpenter \& J. M. Moser \& T. A. Romberg (Eds.), Addition and subtraction: A cognitive perspective (pp. 10-24). Hillsdale, NJ: Erlbaum.

Vergnaud, G. (1990). Problem solving and concept-formation in the learning of mathematics. In H. Mandl, E. De Corte, S. N. Bennett \& H. F. Friedrich 
(Eds.), Learning and instruction: European research in an international context (Vol. 2.2, pp. 399-413). Oxford, UK: Pergamon Press.

Vergnaud, G. (1997). The nature of mathematical concepts. In T. Nunes \& P. Bryant (Eds.), Learning and teaching mathematics: An international perspective (pp. 5-28). Hove: The Psychology Press.

Vergnaud, G. (1998). A comprehensive theory of representation for mathematics education. Journal of Mathematical Behavior, 17, 167-181.

Verschaffel, L., \& de Corte, E. (1997). Word Problems: A vehicle for promoting authentic mathematical understanding and problem solving in the primary school? In T. Nunes \& P. Bryant (Eds.), Learning and Teaching Mathematics: An international perspective. Hove: Psychology Press.

Vilette, B. (2002). Do young children grasp the inverse relationship between addition and subtraction? Evidence against early arithmetic. Cognitive Development, $17,1365-1383$.

Weaver, J. F. (1971). Some factors associated with pupils' performance levels on simple open addition and subtraction sentences. Arithmetic Teacher, 18, 513519. 
Table 1

Example word and digit problems for Experiment 1.

\begin{tabular}{|c|c|c|}
\hline Problem type & Word presentation & Digit presentation \\
\hline $\begin{array}{l}\text { Position } 1 \\
\text { Inverse }\end{array}$ & $\begin{array}{l}\text { Daniel had some cards, he found } 7 \text { more } \\
\text { and then lost } 7 . \text { At the end he had } 13 \text {. } \\
\text { How many did he have to start with } \\
\text { Julia had some balls, she won } 14 \text { more } \\
\text { and then lost } 9 . \text { At the end she had } 18 \text {. } \\
\text { How many did she have to start with? }\end{array}$ & $\square+7-7=13$ \\
\hline $\begin{array}{r}\text { Position } 2 \\
\text { Inverse }\end{array}$ & $\begin{array}{l}\text { There are } 21 \text { children in the classroom, } \\
\text { some more arrive and then } 11 \text { leave. At } \\
\text { the end there are still } 21 \text { children. How } \\
\text { many children arrived? } \\
\text { Melissa had } 15 \text { sweets, she found some } \\
\text { more and then ate } 5 . \text { At the end she had } \\
19 . \text { How many did she find? }\end{array}$ & $15+\square-5=19$ \\
\hline $\begin{array}{r}\text { Position } 3 \\
\text { Inverse }\end{array}$ & $\begin{array}{l}\text { There are } 22 \text { biscuits in the tin, } 7 \text { more } \\
\text { are added and then some are eaten. At } \\
\text { the end there are still } 22 \text { biscuits in the } \\
\text { tin. How many were eaten? }\end{array}$ & $22+7-\square=22$ \\
\hline Control & $\begin{array}{l}\text { There are } 13 \text { children in the pool, } 13 \\
\text { more jump in and then some get out. At } \\
\text { the end there are } 20 \text { children in the pool. } \\
\text { How many got out? }\end{array}$ & $13+13-\square=20$ \\
\hline
\end{tabular}




Position 4
Inverse $\quad$ and then lost 12. At the end, how many
balls did he have?
There are 16 cars in the car park, $16 \quad 16+12-12=\square$
more arrive and then 7 leave. At the
end, how many cars are in the car park?


Table 2

Example inverse and control problems for Experiment 2

\begin{tabular}{|c|c|c|c|c|}
\hline \multirow{2}{*}{$\begin{array}{l}\text { Missing } \\
\text { number }\end{array}$} & \multicolumn{2}{|c|}{ Standard order } & \multicolumn{2}{|c|}{ Rearranged order } \\
\hline & Inverse & Control & Inverse & Control \\
\hline 1 & $\square+7-7=13$ & $\square+14-9=18$ & $\square-9+16=16$ & $\square-3+7=13$ \\
\hline 2 & $13+\square-9=13$ & $15+\square-5=19$ & $14-\square+22=22$ & $18-\square+11=15$ \\
\hline 3 & $16+14-\square=16$ & $18+9-\square=13$ & $9-9+\square=13$ & $11-6+\square=18$ \\
\hline 4 & $15+12-12=\square$ & $11+11-7=\square$ & $8-8+15=\square$ & $8-5+12=\square$ \\
\hline
\end{tabular}


Table 3

Types of inference needed to solve inverse problems with the ' $a$ ' or 'sum' term missing

\begin{tabular}{lll}
\hline Problem & Difficulty & Inference required \\
\hline $\mathrm{b}-\mathrm{b}+\mathrm{a}=\square$ & Easiest & Forward inference with elements adjacent $(0+\mathrm{a}=\square)$ \\
$\mathrm{a}+\mathrm{b}-\mathrm{b}=\square$ & Intermediate & Forward inference across a gap $(\mathrm{a}+0=\square)$ \\
$\mathrm{b}-\mathrm{b}+\square=\mathrm{a}$ & Intermediate & Backward inference with elements adjacent $(0+\square=\mathrm{a})$ \\
$\square+\mathrm{b}-\mathrm{b}=\mathrm{a}$ & Hardest & Backward inference across a gap $(\square+0=\mathrm{a})$
\end{tabular}




\section{Figure Captions}

Figure 1. Accuracy for inverse and control problems compared by position of the missing number from Experiment 1 (error bars show sem).

Figure 2. Accuracy for inverse and control problems in standard and rearranged order compared by position of the missing number from Experiment 2 (error bars show sem).

Figure 3. Accuracy for inverse problems in standard and rearranged order compared by status of the missing number from Experiment 2 (error bars show sem). 


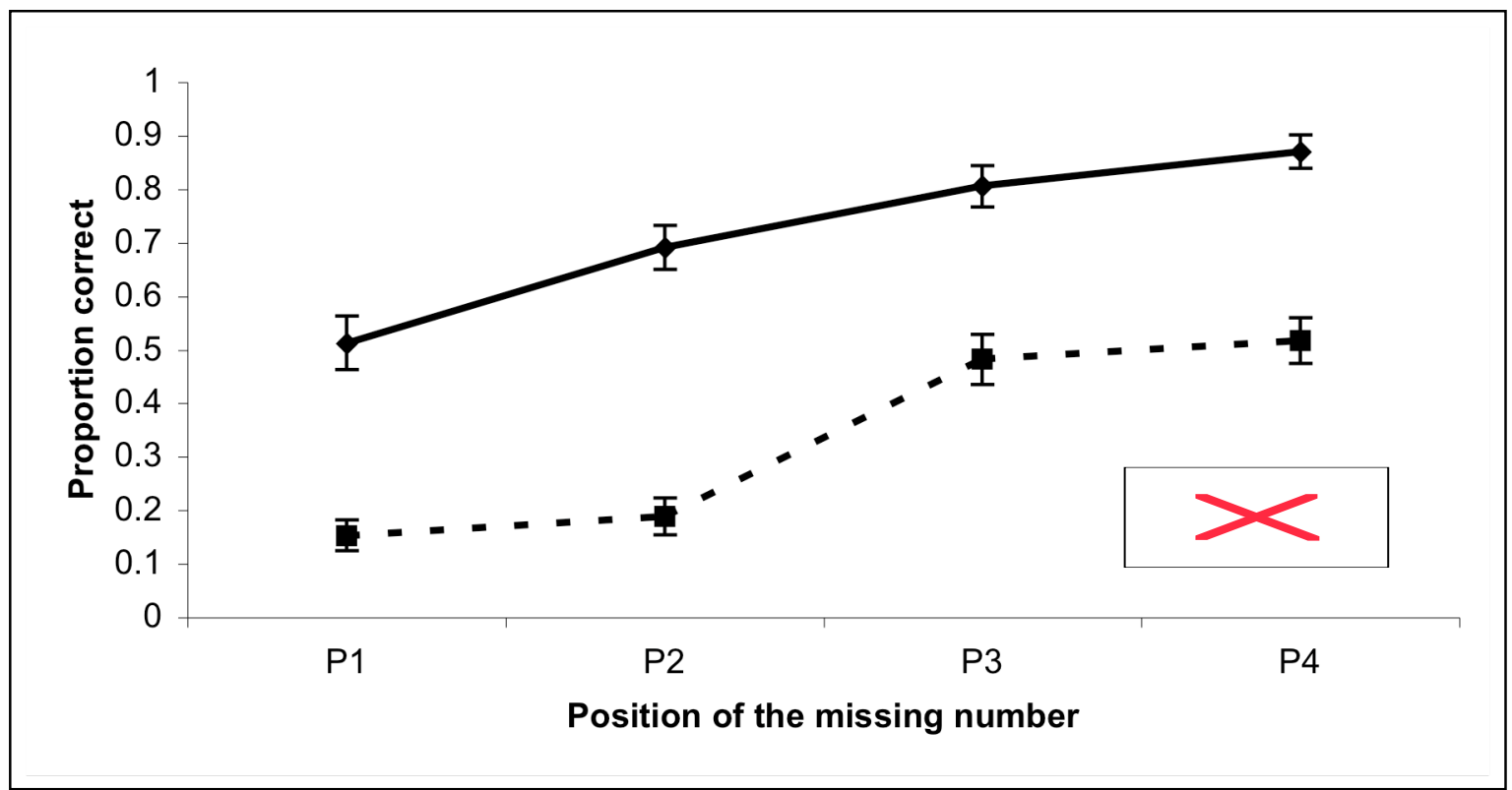




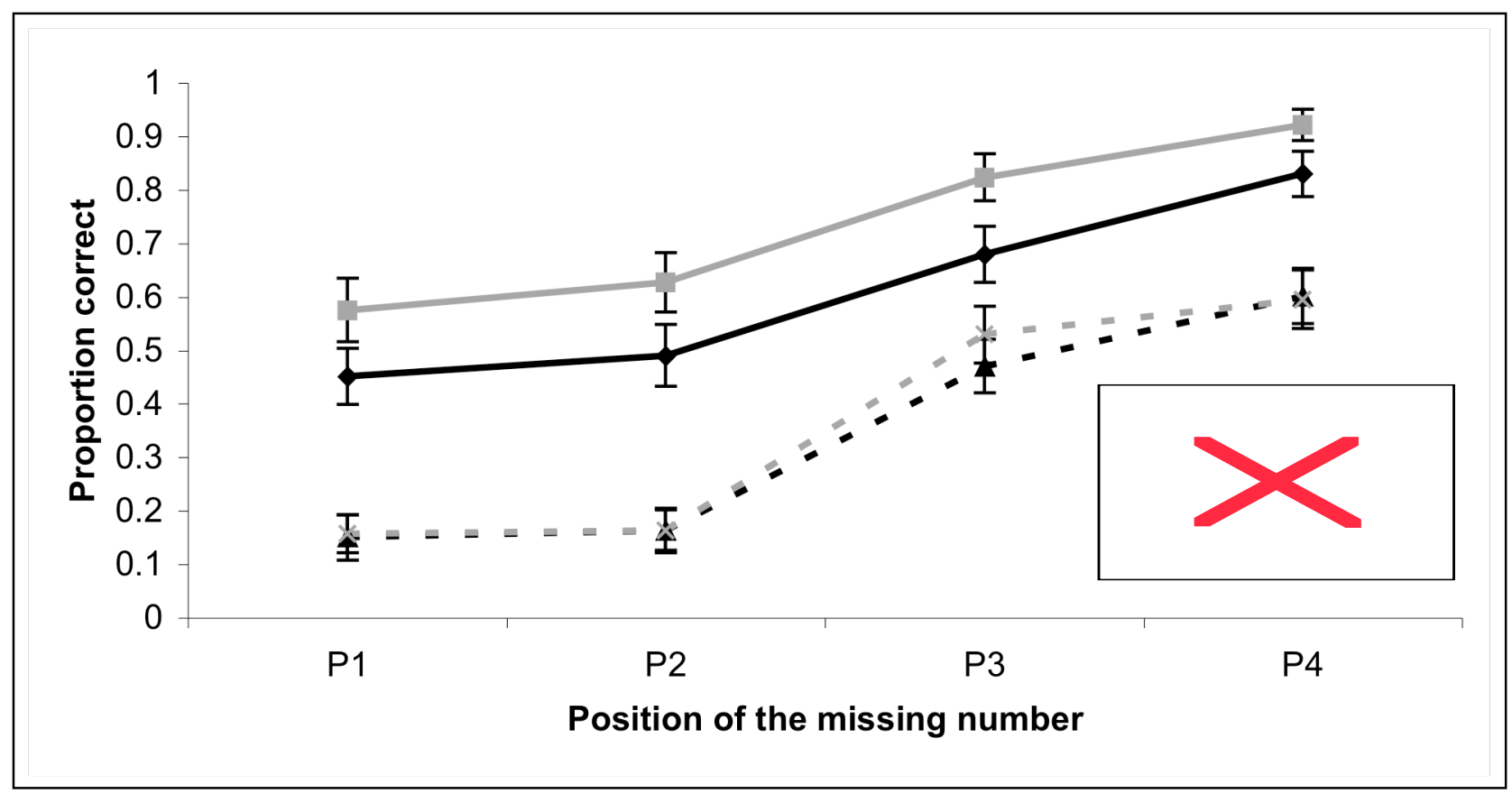




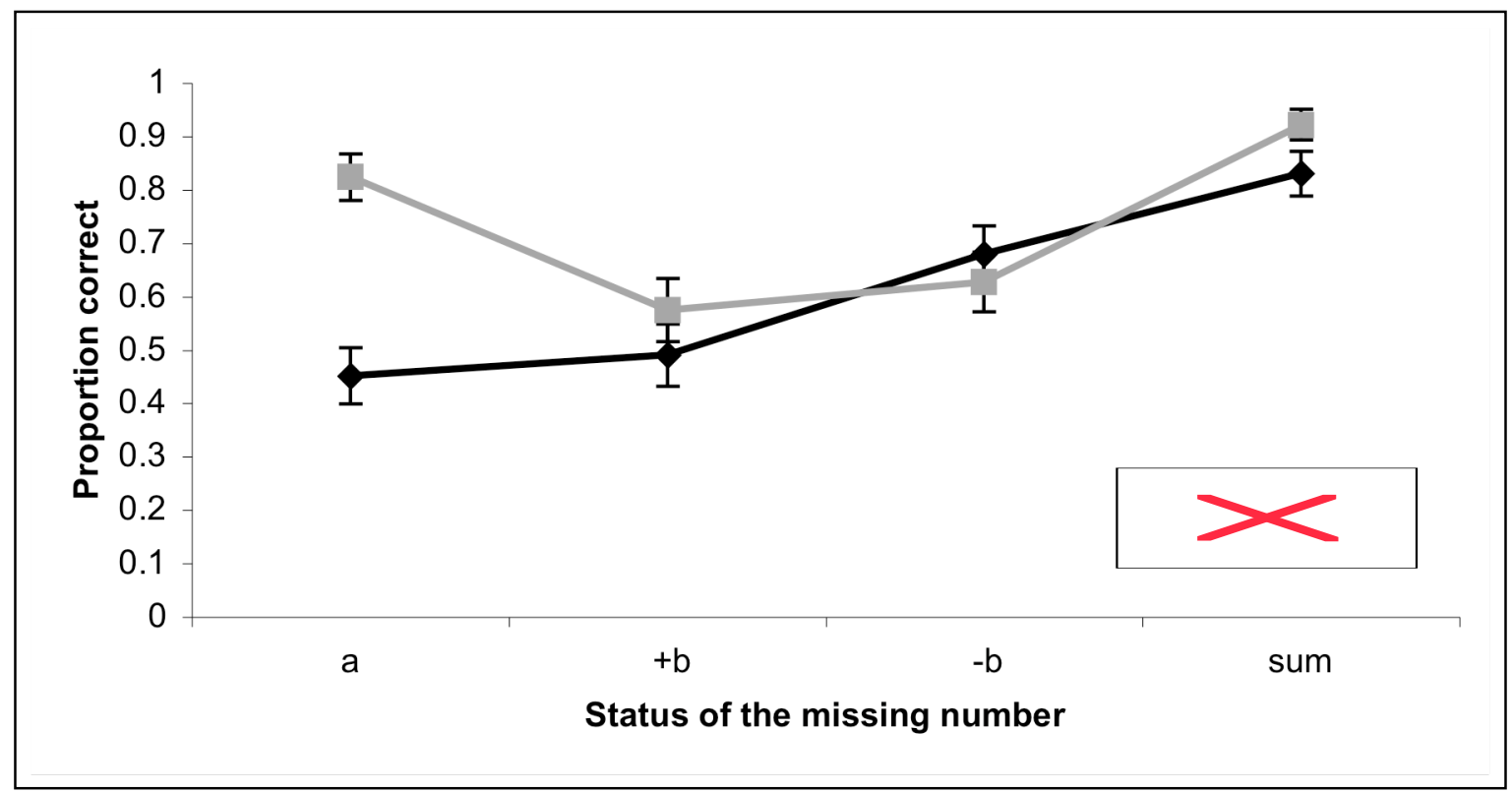

